
\title{
CIÊNCIA'NATURA
}

\section{A construção de instrumentos meteorológicos e o ensino dos elementos do clima em escolas do ensino básico do município de Itaara, RS}

The construction of meteorological instruments and the teaching of climate elements in schools of basic education in the municipality of Itaara, RS

Iago Turba Costa ${ }^{1}$ e Cássio Arthur Wollmann ${ }^{2}$

${ }^{1}$ Graduando em Geografia Licenciatura Plena, Departamento de Geociências, Universidade federal de Santa Maria, Santa Maria/RS, Brasil

inagoturba@hotmail.com

${ }^{2}$ Prof. Doutor, Departamento de Geociências, Universidade federal de Santa Maria, Santa Maria/RS, Brasil cassio.geo@yahoo.com.br

\section{Resumo}

O ensino de Geografia, e principalmente da climatologia deve partir do local de vivência do aluno, pois a maioria dos fenômenos atmosféricos elou climáticos se manifestam e são percebidos pela sociedade em seu espaço imediato, ou seja, no bairro e na cidade. A proposta desse trabalho teve por objetivo, então, introduzir recursos didáticos práticos para o estudo da climatologia junto ao Clube de Ecologia Guardiões das Nascentes nas Escolas Municipal de Ensino Fundamental Alfredo Lenhardt e Escola Estadual de Ensino Médio Itaara na cidade de Itaara - RS. Para iniciar o projeto de pesquisa foi realizada uma revisão bibliográfica a fim de conseguir maior sustentação teórico metodológica para o desenvolvimento do mesmo. Deste modo foi traçada uma metodologia que conceitualmente pudesse ter relevância didática para isso foram propostas metodologicamente atividades a serem cumpridas: Aplicação de nuvens e confeç̧ão de nuvens de um diário do tempo; oficina de observação de algodão; Instalação de cisterna para captação de água da chuva; construção/Instalação de uma mini-estação meteorológica nas escolas. Por fim, com avaliação quanticamente dos recursos aplicados para o ensino da geografia climática escolar, pode-se verificar sua validade enquanto pratica pedagógica, verificando progressos para a com a metodologia proposta.

Palavras-chave: Climatologia geográfica. Elementos climáticos. Recursos didáticos; Estação meteorológica.

Abstract

The teaching of Geography, and mostly of Climatology, must start in the site of experiencing of the student, because the majority of atmospheric and/or climatic phenomena manisfest and are perceived by the society in your immediate area, in other words, in the neighboorhood and the city. This research concerns in to include practical educational resources to the study of climatology with the Ecology Club of Guardioes das Nascentes in the Alfredo Lenhardt Municipal Elementary School and the Itaara State High School in the city of Itaara - RS. That way it was established a methodology with educational relevance with proposed tasks to be accomplished: aplication and confection of clouds from a weather diary; a cotton observation workshop; a cistern installation to collect rain water; construction/installation of meteorological mini station at the schools. With the evolution of the activity, goals to be achieved are created like the appreciation of educational resources for the climatology study, creation of dynamics for the atmospheric phenomena comprehension improving the educational practices of Climatology. Lastly, with quantitative evaluation of applied resources to the teaching of climatic geography, it can be verified it's validity while educational practice, observing progress with the proposed methodology.

Keywords: Geographic Climatology. Weather Elements. Educational Resources; Weather Station. 
O estudo do clima tem por seu objeto/base de estudos a sucessão habitual e gradual dos diferentes tipos de tempo, servindo assim para analisar e compreender os fenômenos climáticos condicionados a relação homem/natureza e sociedade. Esta relação torna-se importante, uma vez que o seu estudo está relacionado como o mais importante de muitos processos naturais e relaciona-se com a percepção ambiental climática de cada indivíduo e seu meio de vida.

Nesse sentido Ayoade (2013, p.286) cita:

O clima talvez seja o mais importante componente do ambiente natural. Ele afeta os processos geomorfológicos,
ou das formacōes dos solos e crescimentos e desenvolvimento das plantas. Os organismos, incluindo o homem, ou das formações dos solos e crescimentos e desenvolvimento das plantas. Os organismos, incluindo o homen,

são influenciados pelo clima. As principais bases da vida para a humanidade, principalmente o ar, que
respiramos é obtido da atmosfera, a a gua que bebemos origina-se da precipitação. (AYOADE, 2013, p.286)

O clima representa papel estratégico na percep̧̧ão do homem ao meio ambiente (SARTORI, 2014), assim os conhecimentos demonstram grande valia, uma vez que seu refinamento em sala deu aula, pode auxiliar os educandos na percepção de fenômenos atmosféricos globais e regionais como forma de reafirmar as relações com o meio ambiente.

A Geografia, assim como todas as outras disciplinas ministradas na escola, tem o compromisso de construir de forma o conhecimento/aprendizagem de forma integrada com uma visão relacional com os conteúdos da grade curricular. Essa dimensão deve proporcionar conexões entre as informações pragmáticas em sala de aula com un aprofundamento maior, possibilitando o aluno ter uma visão mais ampla, profunda e critica de seu ambiente de vivência.

O ensino da geografia tem desta forma um compromisso de desenvolver para com os alunos situações que permitam pensar no contexto espaço-temporal de sua vivência e escala. De acordo com Callai (1998, p.58):

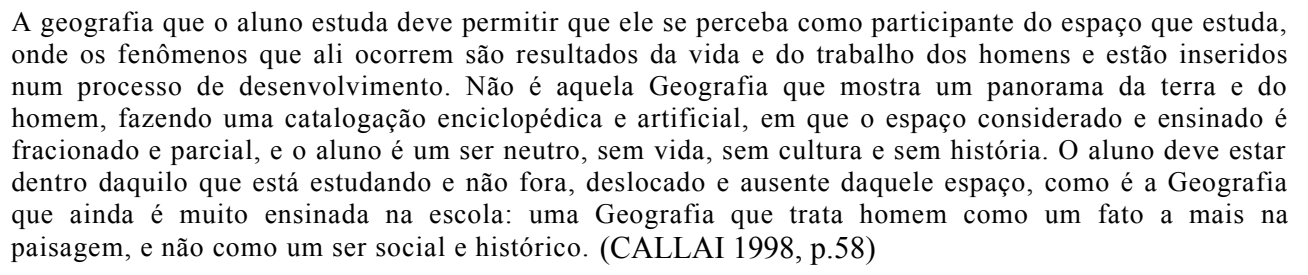

Nesse sentido, o educador deve buscar recursos metodológicos e construir ferramentas para tornar a disciplina mais atrativa, compreensiva e lúdica para os alunos. Efetivando assim uma geografia mais atrativa e que possa contribuir de forma significativa no cotidiano dos educandos. Vindo assim ao encontro da necessidade da geografia que coloca Souza (2007, p. 10) 'um período de renovação teórico-metodológico que caminha no sentido de superar a descrição e memorização dos conteúdos como forma de aprendizagem".

Desta maneira a climatologia, como o elemento natural mais dinâmico dentro da ciência geográfica, sendo presente em qualquer ambiente e influenciador no tanto individuo como sociedade merece atenção no que condiz a sua interpretação e processos pedagógicos. Proporcionando assim, o conhecimento dos elementos climáticos e duas dinâmicas atmosféricas, que podem auxiliar o homem em sua vida cotidiana, por meio do desenvolvimento de seus projetos e influindo na qualidade de vida humana.

O ensino de Geografia carece de novas metodologias e recursos didáticos que propiciem aos educandos maiores participação na construção do conhecimento. O antigo modo de ensinar Geografia, pautado na memorização de conceitos e na dissociação entre o homem e a natureza, não tem mais significação em um novo século onde as inovações tecnológicas impõem ao mundo uma maior conectividade e inter-relações em busca da superação de dicotomias que, em vez de permitir o progresso da ciência geográfica, acabaram por torná-la fragmentada e ideológica.

O ensino da geografia como todas outras as disciplinas ministradas no sistema educacional público deve possuir recursos que possam sair apenas da questão propriamente teórica, focalizando meios lúdicos que sejam práticos e dinâmicos e assim auxiliem o educador na transmissão do conhecimento científico ao educando.

A compreensão climática, desde Monteiro (1969), deve ter por base a análise de sucessão habitual dos tipos de tempo em escala local e regional, sendo os elementos atmosféricos devidamente representados numa escala diária Instituindo assim, um campo significativo dentro do conhecimento da ciência geográfica por parte da climatologia, por parte da formação do cidadão enquanto aplicabilidade do conhecimento, onde mais uma vez coloca Monteiro (1999, p.35)

Os fatos climáticos são uteis a formação do cidadão comum no cotidiano de suas vidas: saber ler un boletim do tempo nos jornais, compreender as relações climáticas nos fenômenos ambientais para



Com isso, para a compreensão sistemática da disciplina, a valorização e inserção de mais recurso didáticos práticos têm grande valia, pois auxiliam positivamente para a fixação dos elementos climáticos a serem estudados na grade curricular básica. A abordagem do conteúdo climatológico está presente nos Parâmetros Curriculares Nacionais (PCN'S), que serve para nortear os discentes sobres os conteúdos básicos a serem abordados na grade curricular escolar. Portes (2010, p. 20) afirma que "As propostas pedagógicas pelos PCNs se constituem em propostas que visam colocar o aluno em diferentes situações de vivência com lugares para que possam construir seus conhecimentos[...]". Assim as práticas pedagógicas escolares lúdicas devem existir, compreendendo o contexto em que o aluno está inserido.

Diante disso, Callai (1998, p. 89) afirma que “[..] a geografia não pode ser ensinada a partir de grandes concep̧̧ões e generalizações", sendo assim, os estudantes devem aprender a partir das particularidades dos fatores dinâmicos climáticos na escala local e regional e posteriormente a global.

Nesse sentido, a proposta desse trabalho foi introduzir recursos didáticos práticos para o estudo da climatologia junto ao Clube de Ecologia Guardiões das Nascentes nas Escolas Municipal de Ensino Fundamental Alfredo Lenhardt e Escola Estadual de Ensino Médio Itaara na cidade de Itaara - RS, os quais serão detalhados adiante neste trabalho.

\subsection{Localização da área de estudo}

O Município de Itaara localiza-se a uma latitude $29^{\circ} 36^{\prime} 35^{\prime \prime}$ sul, e a uma longitude $53^{\circ} 45^{\prime} 53^{\prime \prime}$ oeste, segundo o IBGE (2010), Ross (1996) encontra-se entre a unidade morfo estrutural Planaltos e Chapadas da Bacia Sedimentar do Paraná, região Central do Rio Grande do Sul, aproximadamente no Km 300 da BR-158, a 295 Km da Capital, Porto alegre, e a $14 \mathrm{Km}$ de Santa Maria. Faz limites, ao Norte com Julio de Castilhos (49 km), ao Sul com Santa Maria $(14 \mathrm{~km})$, leste com Santa Maria (Distrito de Arroio Grande $15 \mathrm{~km}$ ) e a oeste com São Martinho da Serra (17 km).

Considerando assim as características geológicas e geomorfológicas do o município está situado nas extensas áreas do topo dos morros residuais que predominam rochas vulcânicas ácidas de básicas da Formação Serra Geral, como basaltos e riólitos. Sendo que no rebordo, possui relevo montanhoso e escarpado, modelado pela erosão hídrica e também predominam o basalto da Formação Serra Geral, na base inferior da encosta pode se encontrar basalto com mistura de arenito. (DOTTO, 2016). 
Em Relação à vegetação a região está inserida no Bioma Mata Atlântica, com predomínio da Floresta Estacional Decidual (IBGE, 2004). Principalmente com vegetação arbórea forma capões e matas de galeria. Na questão hidrológica, o município é divisor de aguas de duas importantes bacias do estado do Rio Grande do Sul: A bacia hidrográfica do rio Vacacaí Mirim, com sua nascente em Itaara e a bacia do rio Ibicuí com sua nascente na cidade de São Martinho da Serra. O município ainda possui duas barragens: Saturnino de Brito e a Val de Serra. (DOTTO, 2016). A Figura 1 representa a localização geográfica do município de Itaara.

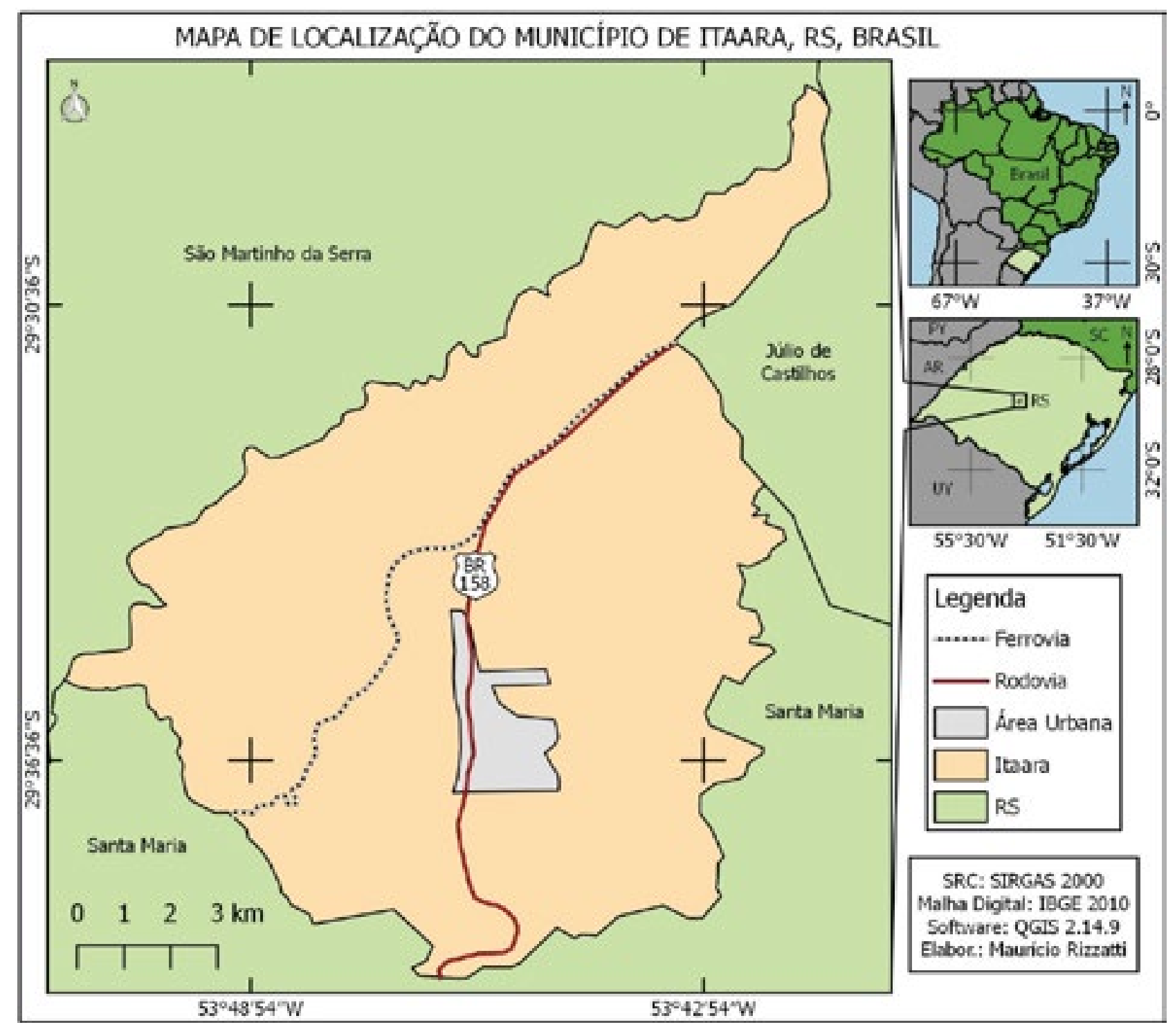

Figura 1-Mapa de localização do município de Itaara, RS, Brasil.

Segundo o IBGE, a população de Itaara é formada por descendentes de alemães, judeus, italianos, portugueses, espanhóis e índios. Segundo o censo demográfico do IBGE (2010), a população total do Município era de 4.578 habitantes, sendo que $72,41 \%$ concentrados na zona urbana e $27,59 \%$ na zona rural, seu Índice de Desenvolvimento Humano Municipal (IDHM) é de 0,760 . O município contém uma área de $172,801 \mathrm{~km}^{2}$, atualmente a população encontra-se aproximadamente em 5.024 habitantes, tendo uma densidade demográfica de 28.96 hab. $/ \mathrm{km}^{2}$
Na questão de instituições educacionais, a cidade conta a presença de 4 escolas, que abrange sendo uma de atendimento infantil, duas de ensino fundamental e uma de ensino médio. Com exceção da Escola de Ensino médio Itaara que provem do poder Estadual, as demais escolas como as de Ensino fundamental Alfredo Lenhart, Euclides Pinto Ribas e Educação Infantil Gralha Azul, são de recursos municipais.

1.2 Aspectos gerais da Educação brasileira no Cenário atual em sala de aula

$\mathrm{O}$ aprimoramento das metodologias em sala de aula deve sempre levar em conta o contexto das realidades ocorridas e presenciadas no cotidiano, onde coloca Castrogiovani (2010, pg. 12): "As ciências passam por mudanças ao longo do tempo, pois as sociedades estão em processo constante de transformação/(re)construção." E assim a leitura dinâmica educacional em sala de aula tem a necessidade adaptar-se ao espaço e tempo, que adquirem novas leituras e dimensões.

Nesse sentido Steinke (2014, pg. 135) afirma que:


aspaço e as interaçōes da sociedade em que vive com a natureza. Dependendo do nivel, o curriculo deve priorizara de estar presente. (STEIKE, 2014, pg. 135)

Desta forma há uma eminente necessidade de construções metodológicas e práticas em sala aula, uma vez que o profissional em educação deve elaborar/construir mecanismos para que os alunos não tenham só um breve entendimento, mas obtenham de forma progressiva um relacionamento mais interagido com seu espaço de vivencia $\mathrm{e}$ assim o possa criar classificações, selecionar informações levantes e dominar conceitos, vindo ao encontro com o que coloca Callai (2010, p.61):

Precisamos encontrar a forma de fazer isso em nas aulas de geografia, considerando a experiência que temos e que
diz a literatura


que the oportunizemos as condiçōes e os instrumentos para que conheça e compreenda a realidade em que vive, CALLAI, 2010, p.61)

Assim, torna-se imprescindível colocar a figura do aluno como ser social em processo de desenvolvimento cognitivo complexo, seguindo o que coloca Paulo Freire (1991, p.14), "Formar é muito mais que do que puramente treinar o educando no desempenho das destrezas", assim, leva-se em conta o processo de construção do "ser" em sua perspectiva social e evolutiva, onde a escola passa agregar em suas competências o discurso e efetividade dos conteúdos específicos utilização na vida do aluno.

De forma coerente ao exposto, nota-se uma crescente tentativa de reformulação/reconstrução de forma de abordagem pratica e métodos, que a ciência geográfica consiga trabalhar de forma efetiva com a percep̧ões em diferentes escalas ao delimitar o espaço de abordagem perceptivo ao homem

1.3 A Importância da Climatologia no Ensino da Geografia

A abordagem da climatologia é essencial para ciência geográfica, sendo importante para estudo ambiental, onde a relação tempo clima não pode ser colocada de lado. Dentro da relação entre os quatro domínios globais (atmosfera, hidrosfera, litosfera e biosfera), o clima entra nessa relação como agentes potencializadas e necessário em todas etapas 
desse sistema, desde a formação e modelagem do solo e relevo até a circulação atmosférica geral referindo-se a passado e presente (AYOADE, 2013).

Entendo a importância dessa definição coloca AYOADE (op. cit., p. 2) que "na ciência da atmosfera, usualmente é feita uma distinção entre tempo e clima, [...]. Por tempo, conforme o autor, entende-se o estado médio da atmosfera numa dada porção de tempo e em determinado local. Por outro lado, clima é a síntese do tempo num dado lugar durante um determinado período de aproximadamente 30-35 anos (AYOADE, 2013). Criando-se a necessidade de se abordar os conteúdos em sala de aula, buscando potencializar a aprendizagem. No que diz respeito ao conteúdo da climatologia geográfica, torna-se mais atraente os olhos dos educandos.

Diante disso SILVA (2007, p. 46) que destaca:

O estudo do clima no Ensino Fundamental a partir da construção de uma mini-estação meteorológica de superfíici com a utilização de materiais alternativos
climatologia (SILVA, 2007, p. 46).

Assim, a estação meteorológica dentro do proposto torna-se de suma importância na construção conhecimento prático, uma vez que os educandos participaram de sua construção. Seguindo a necessidade de se trabalhar formas práticas do conteúdo climatológico no que se refere aos tipos de nuvens coloca Ayoade (2013 p.149);

As nuvens são agregadas de gotículas d'água muitissimo pequenas, de cristas de gelo, ou uma mistura de ambo com suas bases bem acima da superficie terrestre. As nuvens são formadas principalmente por causa do
movimento vertical do ar úmido, como na conveccão, ou na ascensão forçadas sobre as áreas elevada, ou no movimento vertical em longa escala, associado a frentes e depressões.

Desta forma as nuvens são classificadas em tipos com base em dois critérios, sendo eles; aspecto, estrutura e forma ou aparência da nuvem e a altura na qual a nuvem ocorre na atmosfera. Assim as principais nuvens são; cirrus, cirrocumulos, cirrostratus, altocumulos, estratocumulos, nimbos, cúmulos, e stratus que podem ser observadas na Figura



Figura 2- Os principais tipos de nuvens,

Fonte: Avoade (2013. no.150
Podendo assim, fazer uma evolução didática para poder inferir os diferentes tipos de precipitação classificas em três tipos principais, "tipo convectivo de precipitação associado a instabilidade convectiva, precipitação do tipo ciclônico associada com a convergência em sua depressão, precipitação orográfica associada às áreas acidentadas ou montanhosas" AYOADE (2013, pg. 161). Assim Rossato; e Silva (2007 p. 104) vem de encontro nessa mesma relação colocando:

Nesse sentido, é importante analisar como o clima é abordado em sala de aula. Nota-se que a geografia ainda se

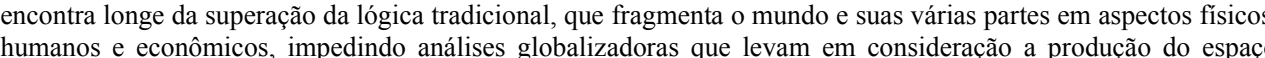
como fruto das dinâmicas sociais. (ROSSATO; e SILVA, 2007 p. 104)

Refletindo sobre o exposto, $o$ ensino da climatologia não pode fugir da sua importância social, procurando-se fugir de clichês e do senso comum, não se pode deixar de afirmar que sua presença e suas consequências são inevitáveis a qualquer ser social e todas as sociedades. Assim, deve-se que construir por parte em sala de aula modos, em que se trabalhe de forma estreita a ralação entre as condições climáticas em sua relação com a vivência em sociedade e comunidade, possibilitando o aluno de poder construir uma relação de participação e dependência do clima em sua vida.

\subsection{Mini cisterna de baixo custo}

A água é um recurso natural essencial para sobrevivência dos seres humanos, diante é de grande importância o pensar em seu uso racional, uma vez que seu desperdício pode ocasionar problemas de racionamento. Diante disso, a captação pela água da chuva na forma de uma cisterna é um valor considerável.

Nesse sentido observando o modelo proposto por Ferreira; J.S; Almeida; M.C (2015) de um modelo de baixo custo de uma cisterna, como mostra a Figura 4- Esquema de uma mini-cisterna de baixo custo.

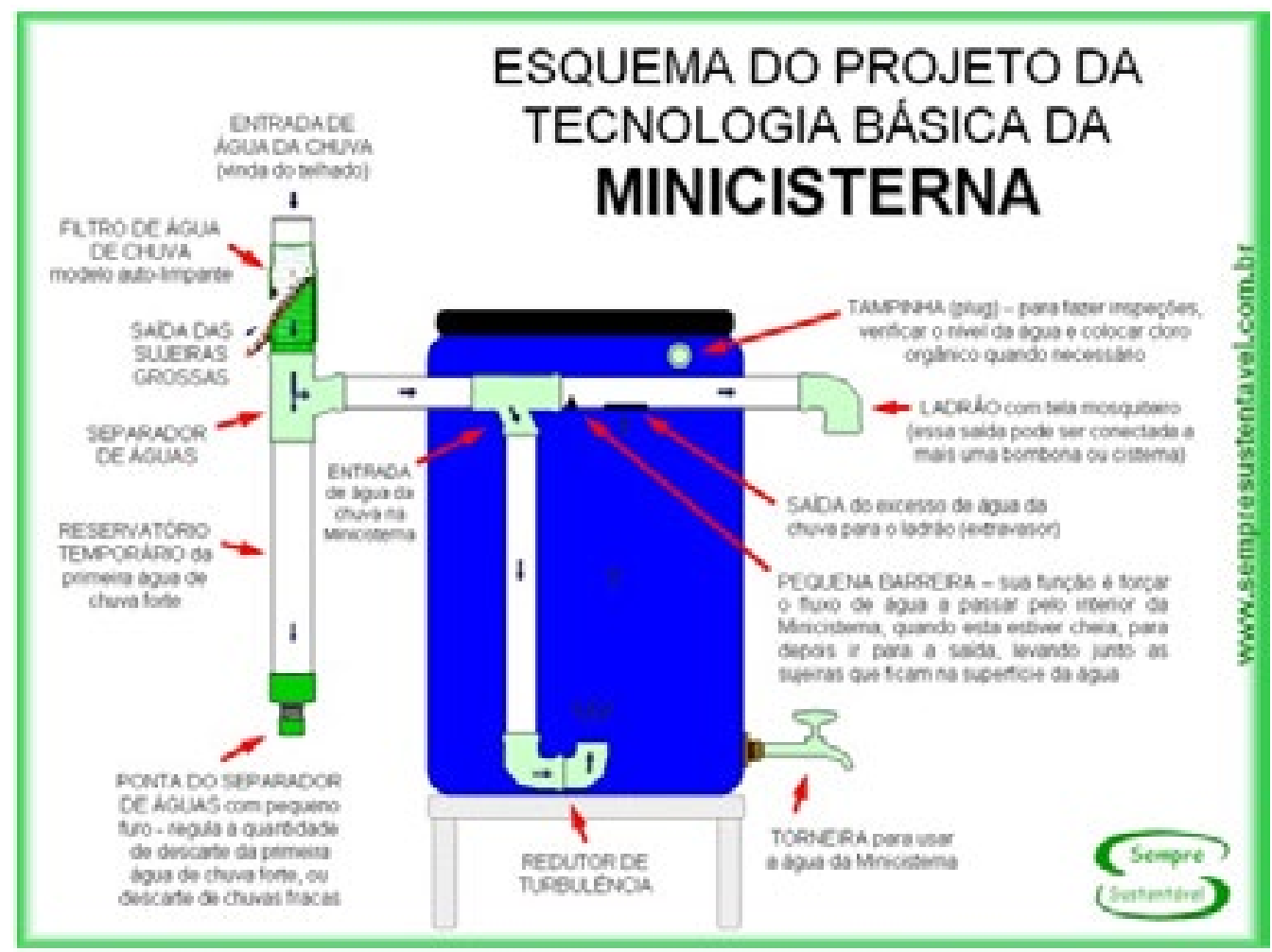

Figura 4- Esquema de uma mini-cisterna de baixo custo. Arquivo: Organização Sempre sustentável Elaboração: Ferreira, J. S.; Almeida, M. C., (2015) 
Com esse modelo, há a possibilidade de construção de uma cisterna com um menor custo possível, uma vez que os materiais são de facilmente encontrados em lojas de matérias de construção. Também há a possibilidade de a população em geral possuir um mini-cisterna em sua residência aproveitando as possíveis calhas existentes.

Este pressente trabalho tem por objeto aplicar ferramentas de auxílio a aprendizagem da climatologia por meio de oficinas lúdicas que auxiliem na construção e Instalação de uma miniestação meteorológica nas escolas.

Para o alcance desse objetivo geral foram traçadas atividades a serem cumpridas, pelos seguintes objetivos específicos:

- Oficina de observação de nuvens e confecção de nuvens de algodão;

- Construção/instalação de uma mini-estação meteorológica e aplicação de um diário do tempo

- Instalação de cisterna para armazenamento e captação da água da chuva.

- Avaliar de forma qualitativa se os mecanismos aplicados são uteis e validos a prática pedagógica.

\section{Materiais e Métodos}

Baseando-se na revisão bibliográfica buscou-se conseguir maior sustentação teórico-metodológica para o desenvolvimento do mesmo. Logo, para mais embasamento respeitando as diretrizes nacionais, os conteúdos do Ensino Fundamental e Médio dando ênfase no conteúdo de Climatologia da instituição selecionada, tendo como base os PCN's de geografia, que acolhem a temática do clima, para assim ser proposta uma metodologia de forma adequada às margens da educação brasileira e a climatologia geográfica regional, ou seja, a realidade local.

As escolas selecionadas pertencem ao município de Itaara- RS: Escola Municipal de Ensino Fundamental Alfredo Lenhardt e Escola Estadual de Ensino Médio Itaara. Ambas participantes do Clube de Ecologia Guardiões das Nascentes, projeto voltado a Educação Ambiental, organizada pela Fundação MO'Ã. O projeto da fundação em Itaara recebia apoio em parceria com a Petrobrás, onde o projeto que buscava trabalhar meios sustentáveis em relação ao ambiente geográfico da cidade. Com relação a esse trabalho foram participantes 30 alunos de ambas as escolas, no ensino fundamental, alunos do sétimo ao nono ano e no ensino médio alunos do primeiro e segundo ano.

A pesquisa contempla então 5 etapas, sendo que nas 3 primeiras ocorreram a inserção de recursos didáticos sobre elementos pedagógicos do clima. Já na última etapa sendo realizada a instalação de uma mini cisterna de baixo custo.

No primeiro encontro de cada turma foi realizada uma introdução aos conceitos climáticos e definição de fenômenos climáticos como a diferenciação de tempo e clima. Deste modo proporcionando aos alunos uma aula expositiva sobre os conteúdos e conceitos propostos.

Na segunda etapa foi elaborado um guia de confeç̧ão de nuvens de algodão de forma que possam auxiliar na parte conceitual que será aplicado com as definições e conceitos sobre os diferentes tipos de nuvens.

Para a confecção das nuvens de algodão foi utilizada uma caixa de madeira (descartada de feiras), algodão, barbante, tesoura, tinta azul (representar o céu), tinta verde (representar o solo) e cola. Os tipos de nuvens trabalhados nesta etapa são o mesmo modelo citado na fundamentação teórica, os quais foram representados pelos alunos na forma de algodão.

Em numa terceira etapa, foi realizada a instalação de uma estação meteorológica nas escolas em questão, sendo confeccionado por cada aluno um diário do tempo (anexo A), que conteve dados climáticos por um determinado período e posteriormente será feito as conclusões sobre os dados coletados. A estação meteorológica (figura 5), tendo por objetivo potencializar e elucidar os conteúdos postos em questão. Foram observados assim os modelos estação metodológica de Hoppe et. al. (2015) e Armani e Galvani (2006).

Para a construção do anemômetro, foram utilizados palitos finos, cola, tesoura, fundos de garrafas pets de $600 \mathrm{ml}$ tinta para plástico de cores variadas e rolha de garrafa. Neste instrumento apenas a tinta para plástico foi comprada, os demais materiais foram conseguidos em descartes. Por fim o anemômetro é fixado na parte de cima a estação meteorológica

Já na quarta e última etapa aproveitando a estrutura física dos colégios foi instalada uma mini-cisterna conforme modelo Ferreira; J.S; Almeida; M.C (2015), aproveitando as calhas existentes no telhado de ambas as escolas. De modo a se respeitar os conceitos de equidade e sustentabilidade citados no relatório da ONU (2011), a cisterna ajudara na infraestrutura das escolas, onde toda água armazenada será utilizada pelos funcionários em atividade de limpeza. Os materiais utilizados para a cisterna conforme metodologia já citada foi tambor de 200 litros, conexões em PVC, tela mosquiteiro, torneira de agua de plástico, parafusadeira elétrica, durepóxi. Todos os materiais para esta etapa foram doados pela fundação Mo’ã.

Numa última etapa, foi realizada uma avaliação das oficinas propostas anteriormente, para fim de verificar sua validade e poder recomendar ou não sua aplicabilidade posterior. A avaliação foi feita de forma adaptado ao método de observação conforme o modelo de avaliação mediadora criado por Hoffmann, que consistiu na observação do (s) aluno (s) em todas as etapas de forma individual e coletiva, pela coleta de dados da estação meteorológica e também por um questionário aplicado de forma coletiva para os todos 30 participantes no final de todas as atividades.

\section{Análise e discussão dos dados}

Na primeira etapa, na qual foi concedida aula teórica para os alunos, sobre os fenômenos e elementos atmosférico de forma geral. Sobre os fatores climáticos foram trabalhados a distribuição da energia solar sobre a superfície terrestre, com a questão da rotação e translação da terra e também pela inclinação latitudinal, e a diferença de altitude. Sobre os elementos climáticos foram trabalhados a questão da temperatura, umidade, pressão atmosférica, tipos de chuvas, ventos e pôr fim a movimentação e formação das principais massas de ar. Deste modo foi observado que a maioria não tinha conhecimento sobre os conceitos abordados. Desta maneira, a pratica teórica contribuiu para seguimento do trabalho.

Os alunos em sua maioria (coletivo) prestaram atenção na aula, alguns participaram e tiraram dúvidas sobre os conceitos abordados. Uma das partes que mais chamou atenção por parte dos alunos foi a questão da altitude atmosférica, o qual eles relacionaram a diferença de altitude em relação a cidade de Santa Maria. A figura 6 mostra o momento de aula teórica. 


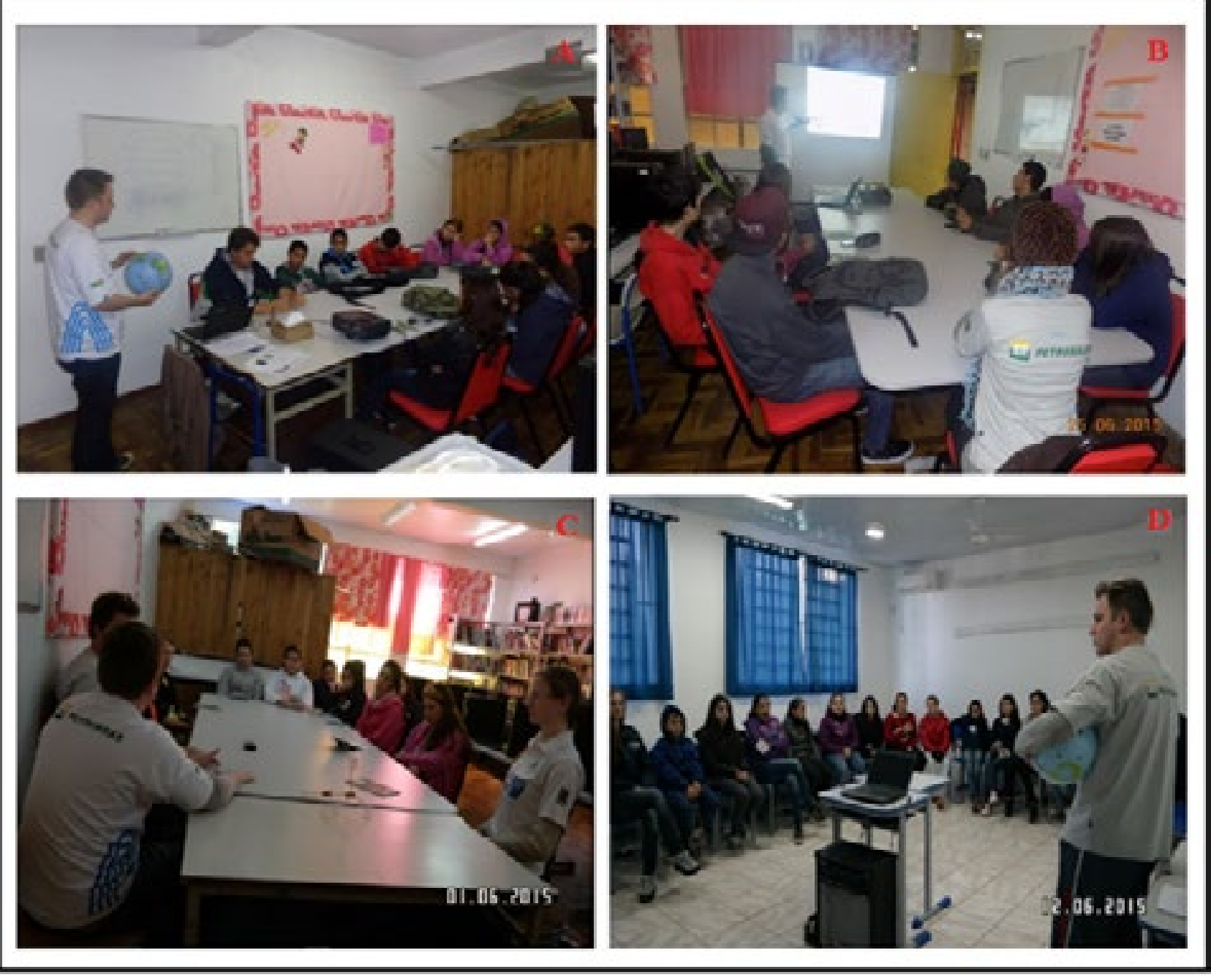

Figura 6- Aula Teórica: Alunos da Escola Alfredo Lenhart (A e B) e Alunos da Escola Itaara (C e D) Fotografia: Arquivo fundação MO'Ã Organização: Os autores

A oficina de observação e confecção de nuvens de algodão deu continuidade as atividades propostas na segunda etapa de forma teórica e prática. Primeiramente foi conceituada a definição de nuvem, bem como sua formação, diferentes tipologias baseando-se no aspecto físico (estrutura e forma) e principais ocorrências.

Nesta etapa os alunos mostraram-se muito mais interessados, principalmente por ser uma parte pratica, e pelo uso de matérias como cola algodão e tinta. Outro ponto de destaque, que a maioria trouxe algumas dúvidas de casa, sobre a formação das nuvens, deslocamento e principalmente a nome nomenclatura delas. Como mostra na figura 7.

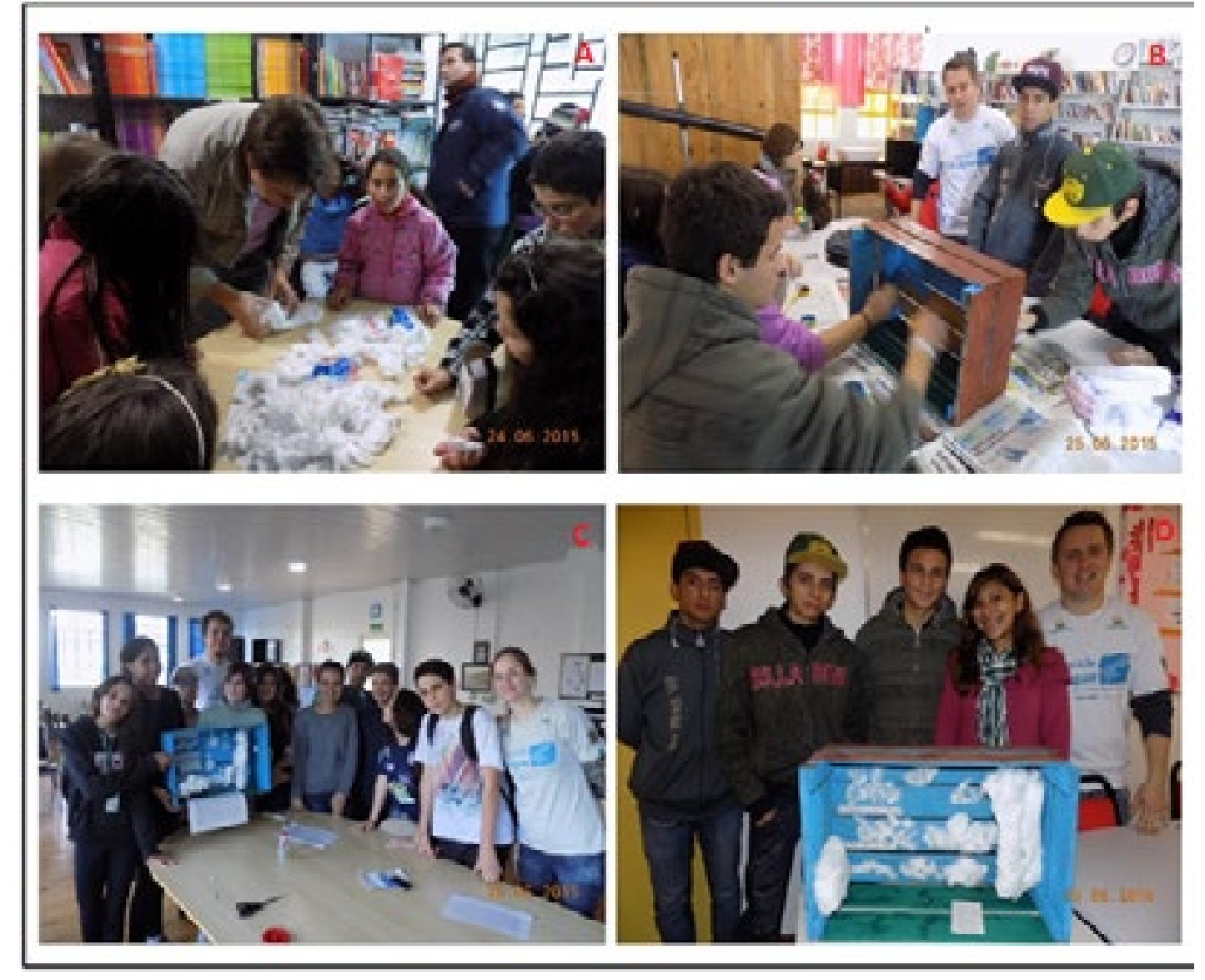

Figura 7- Oficina de observação e confecção de nuvens de algodão: elaboração (A e B) e finalização (C e D). Organização: Os autores (2016).

Alguns dos alunos que auxiliaram no processo de montagem confecção dos instrumentos, relataram que seu pais tinham alguns desses instrumentos em casa, principalmente o pluviômetro. Deste modo, está relacionado pela maioria dos alunos serem de um ambiente rural e seus pais possuírem pequenas hortas em casa, ou bem como serem agricultores. De mostrando deste modo, em ralação a avaliação mediadora que o meio econômico e social, configurando e espaço vivido do aluno pode e dever ser colocado ser abordado e relacionado de forma que ele possa não só fixar o conteúdo, mas sentir-se participante e da formação de seu próprio conhecimento



Figura 9- Confeccão do barômetro. Fotografia:
Organização: Os autores (2016). 
A última etapa prática foi construção e instalação da estação meteorológica (figura 10) nos pátios de ambas escolas em terreno que possuía cobertura vegetal a fim de diminuir a relação, com sua frente voltada ao sul magnético a fim de não incidir diretamente os raios solares. O termômetro de mercúrio para medição da temperatura e o pluviômetro, foram ambos comprados pela fundação MO’A e respectivamente instalados parte de dentro e fixado na parte de trás da estação.

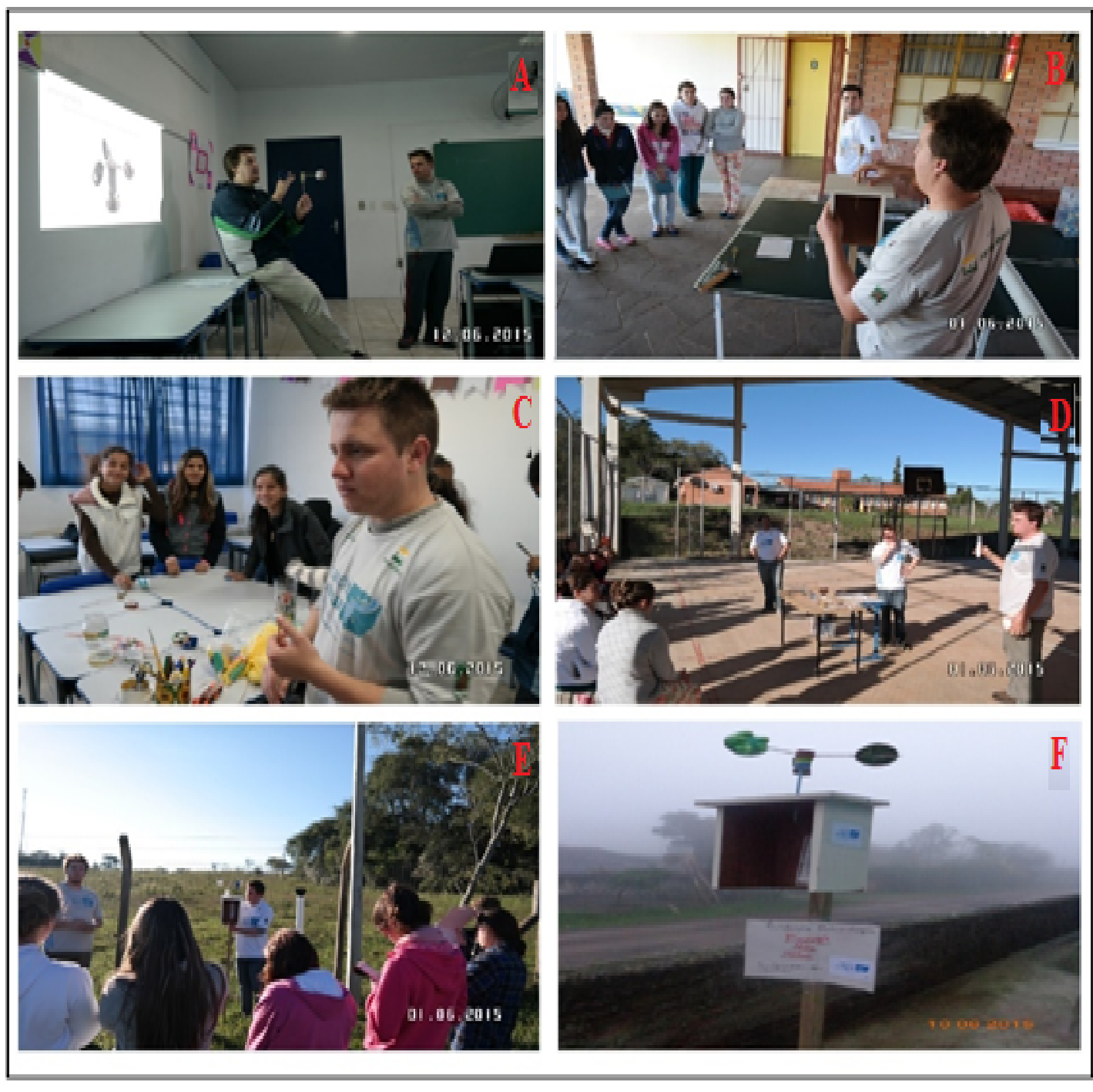

Figura 10- Confecção da miniestação meteorológica: Confecção ( A, B, C e D) e Instalação (E e F). Fotografia: Arquivo fundação MOA.
Organizą̧ão: Os autores (2016).

Com o termino da instalação da estação meteorológica construído por cada escola um diário do tempo onde anotaram dados de elementos do tempo atmosférico. Durante 18 dias seguidos foram coletados no período do recreio do cada escola, por volta das 10 horas e 15 minutos da manhã os dados podendo ser verificado nas tabelas 1 e 2, nível de precipitação, temperatura, umidade relativa do ar, velocidade do vento, e nebulosidade.
Tabela 1- Diário do tempo elaborado por alunos da Escola Municipal de Ensino Médio Itaara - Elaboração: Alunos projeto guardiões das nascentes da escola Itaara

\begin{tabular}{c|c|c|c|c|c}
\hline Data & Precipitação $(\mathrm{mm})$ & Temperatura $\left({ }^{\circ} \mathrm{C}\right)$ & Umidade & Vel. do vento & Nebulosidade \\
\hline $08 / 09$ & 0,0 & 15 & Baixa & Brisa fraca & Poucas nuvens \\
\hline $09 / 09$ & 0,0 & 19 & Baixa & Calmaria & Céu limpo \\
\hline $10 / 99$ & 0,0 & 17 & Baixa & Calmariaa & Céu limpo \\
\hline $11 / 09$ & 0,0 & 18 & Baixa & Calmaria & Cúu limpo \\
\hline $12 / 09$ & 0,0 & 25 & Baixa & Brisa Forte & Poucas nuvens \\
\hline $13 / 09$ & 31,0 & 15 & Alta & Brisa moderada & Nublado \\
\hline $14 / 09$ & 0,0 & $14^{\circ}$ & Baixa & Brisa forte & Poucas nuvens \\
\hline $15 / 09$ & 0,0 & 14 & Baixa & Calmaria & Céu limpo \\
\hline $16 / 09$ & 0,0 & 19 & Baixa & Calmaria & Poucas nuvens \\
\hline $17 / 09$ & 0,0 & 17 & Baixa & Brisa Leve & Céu limpo \\
\hline $18 / 09$ & 0,0 & 14 & Baixa & Brisa forte & Poucas nuvens \\
\hline
\end{tabular}

Organização: Os autores (2016)

Tabela 2 - Diário do tempo elaborado por alunos da Escola Estadual de Ens. Fundamental Alfredo Lenhart Elaboração: Alunos do projeto Guardiões das Nascestes da escola Alfredo Lenhart.

\begin{tabular}{c|c|c|c|c|c}
\hline Data & Precipitaç̃o $(\mathrm{mm})$ & Temperatura $\left({ }^{\circ} \mathrm{C}\right)$ & Umidade & Vel. do vento & Nebulosidade \\
\hline $08 / 09$ & 0,0 & 18 & Baixa & Brisa fraca & Poucas nuvens \\
\hline $09 / 09$ & 0,0 & 20 & Baixa & Calmaria & Céu limpo \\
\hline $10 / 09$ & 0,0 & 19 & Baixa & Calmaria & Céu limpo \\
\hline $11 / 09$ & 0,0 & 19 & Baixa & Calmaria & Céu limpo \\
\hline $12 / 09$ & 0,0 & 24 & Baixa & Brisa Forte & Céu limpo \\
\hline $13 / 09$ & 30,0 & 16 & Alta & Brisa & Nublado \\
\hline $14 / 09$ & 0,0 & 15 & Baixa & Brisa forte & Poucas nuvens \\
\hline $15 / 09$ & 0,0 & 15 & Baixa & Calmaria & Céu limpo \\
\hline $16 / 09$ & 0,0 & 19 & Baixa & Calmaria & Poucas nuvens \\
\hline $17 / 09$ & 0,0 & 17 & Baixa & Brisa Leve & Ćú limpo \\
\hline $18 / 09$ & 0,0 & 15 & Baixa & Brisa forte & Poucas nuvens \\
\hline
\end{tabular}

Organização: Os autores (2016)

Observando os dois quadros, percebe-se que a maior diferença entre ambas é a temperatura. O que é explicado a diferença de localização, sendo a Alfredo Lenhart localizada no centro da cidade, onde existe mais presença de construções e calçamento pavimentado ao seu entorno, diferente da Escola Itaara, que está localizada em um espaço mais arbóreo e possuindo mais cobertura vegetal ao seu redor

Na última etapa de ensino e pesquisa pratica conforme a metodologia proposta foi confeccionada junto aos alunos uma mini cisterna de baixo custo para captação de água, aproveitando na escola de Ensino Médio Itaara uma calha já existente no espaço físico da escola. Já na escola de Ensino Fundamental Alfredo Lenhart, precisou ser confeccionada com os alunos uma
calha de matéria PVC para instalação da Cisterna. Como mostra na figura 12 


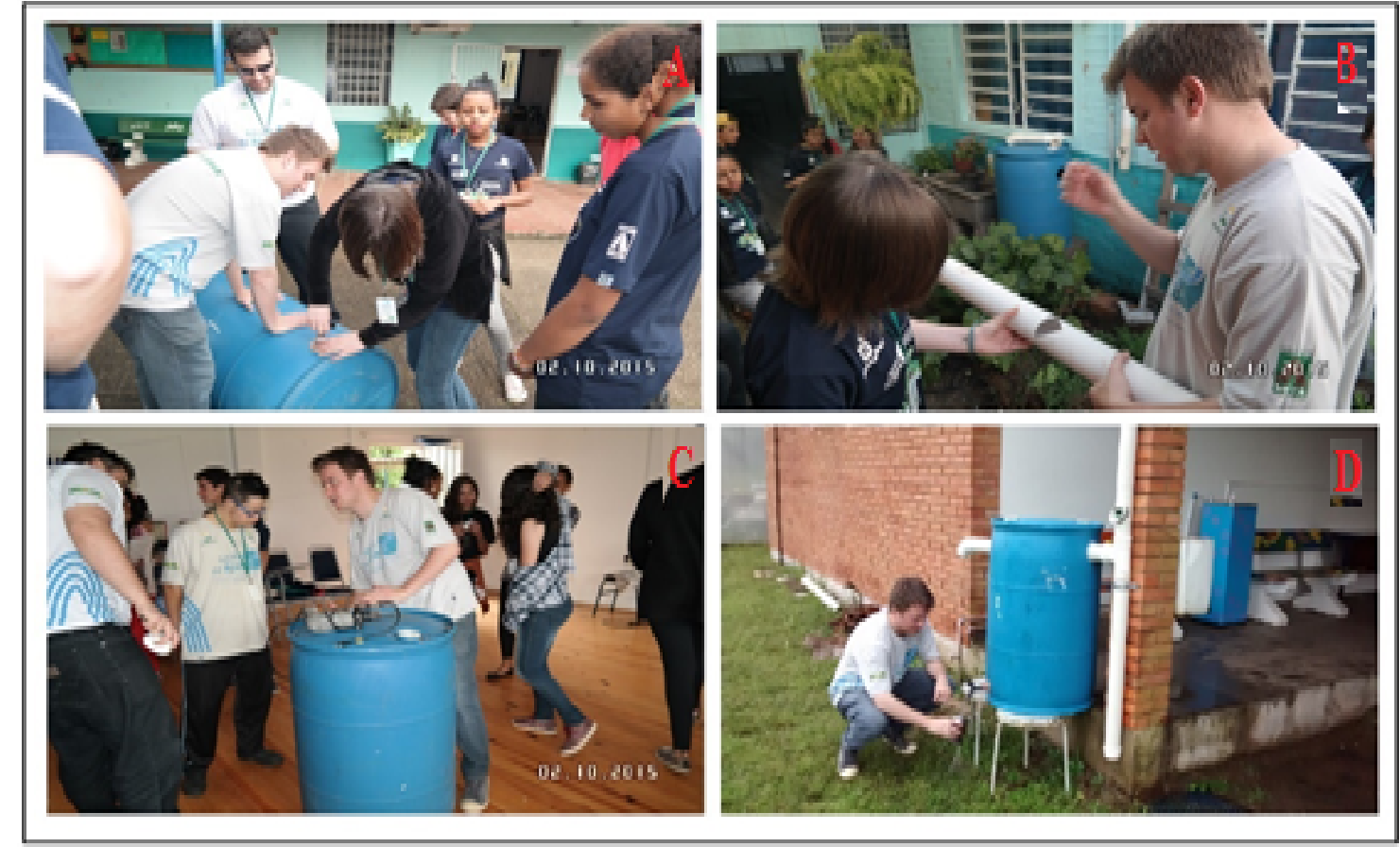

Figura 11- Confecção da mini cisterna de baixo custo: Construção (A, B e C) e Instalação (D). Fotografia: Arquivos fundação Mo'a

Os alunos foram participantes desse processo, ajudando na construção das peças necessárias e posteriormente na montagem e instalação da cisterna. Ficaram satisfeitos ao verem a água sendo coletada para uso dos funcionários da escola. E perguntaram se seria possível a instalação de uma cisterna em casa teriam economia de água, sendo utilizada principalmente pelas mães

Com relação ao questionário que foi dividido em duas partes, sendo a primeira parte de cunho mais objetiva e a segunda subjetiva/dissertativa. Com relação a primeira questão que indagava sobre os fatores climáticos abordados e Itaara foram possíveis de serem identificados. Resultados são demonstrado no gráfico da figura 12.

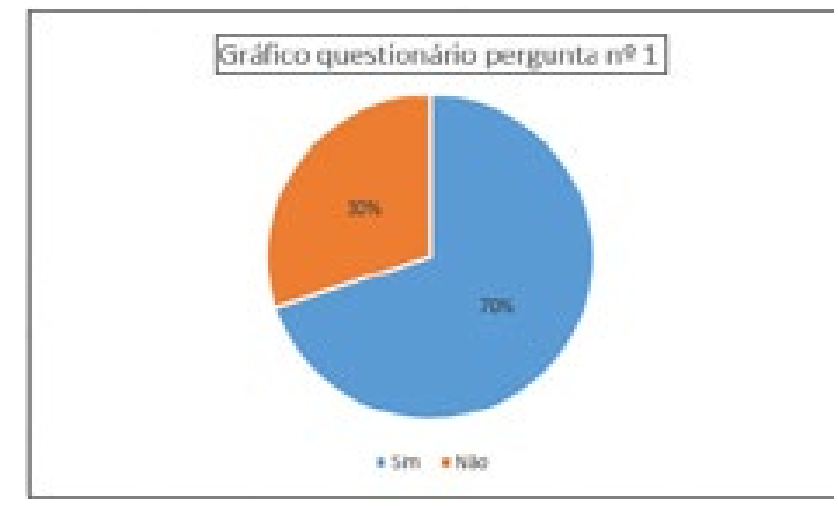

Figura 12 - Questão n n 1 se é possivel identificar os fatores atmosféricos estudados em Itaara.

Nesta indagação $70 \%$ dos alunos disseram que conseguiam identificar os elementos ou fatores climáticos estudados e $30 \%$ disseram que não conseguiam. Dos alunos que responderam sim, em sua maioria falou da questão da altitude atmosférica relacionando com aue o municínio de Itaara está em uma maior altitude aue municínio Santa Maria.
Na pergunta 2 foi abordado o tema da diferenciação tempo e clima e na avaliação se o diário do tempo auxiliou para o entendimento dos elementos climáticos. Neste quesito $80 \%$ dos alunos avaliaram que o diário do tempo auxiliou significativamente para compreensão dos conceitos e diferença entre tempo atmosférico e clima, outros $20 \%$ marcaram que este procedimento auxiliou parcialmente. $\mathrm{O}$ gráfico da figura 13 demonstra o resultado.

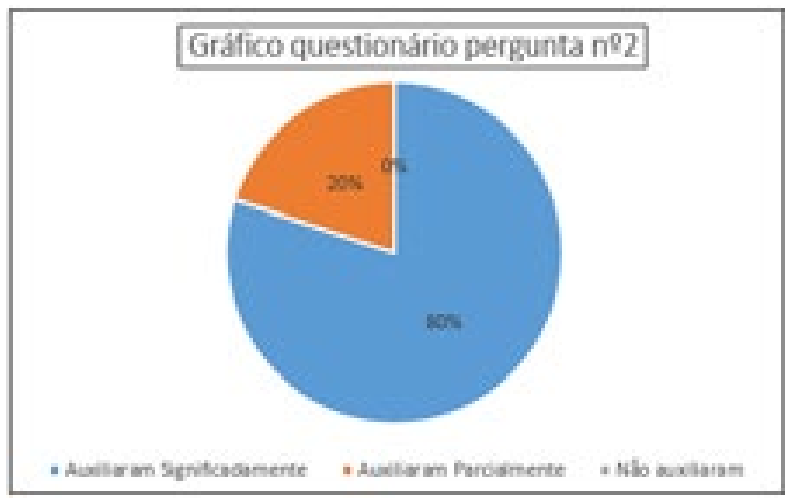

Figura 13 - Questão no 2 , se foi possível entender a diferença ente tempo-clim

Na questão 3 foi indagado o elemento atmosférico que chamou mais atenção no preenchimento do diário do tempo. A maioria dos alunos citaram que a temperatura e nebulosidade foram os elementos que mais chamaram a atenção. Neste caso a temperatura por ser um elemento que está presente diariamente na vida dos alunos e nebulosidade pela questão visual, de precisar olhar todos os dias para o céu, o que não faziam antes com tanta frequência para avaliar as nuvens.

Na questão 4 (Figura 14) referia-se sobre a confecção do observatório de nuvens de algodão e o auxílio para a identificação dos diferentes tipos de nuvens e sua formação. Nesta pergunta $73 \%$ responderam que conseguiram compreender o processo de formação e identificar os tipos de nuvens e os demais $27 \%$ compreenderem boa parte, mas tem alguma dúvida ou dificuldade de identificar todos os tipos de nuvens.

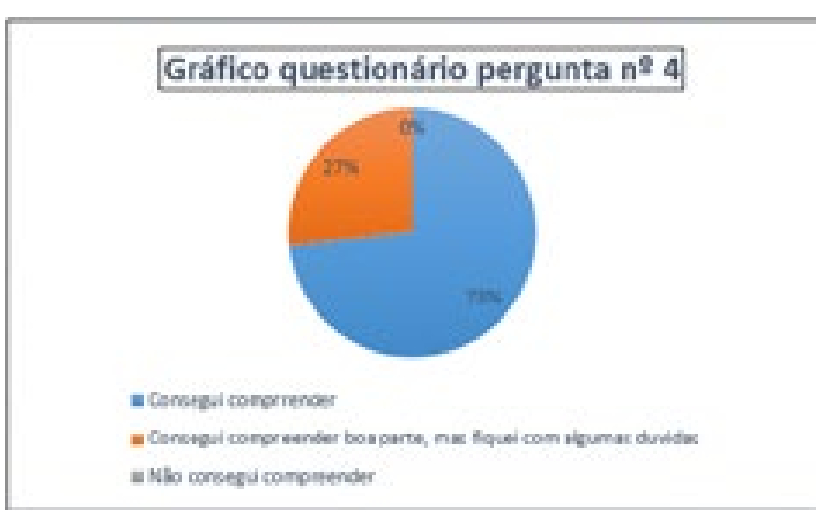

Figura 14 - questão de ${ }^{\circ} 4$, se o observatório de nuvens auxiliou para identificação dos tipos de nuvens e suas formações.

Em relação a pergunta $n^{\circ} 5$ (figura 15) do questionário que tratava da instalação da cisterna e do funcionamento dos mecanismos dos mecanismos necessários para sua Instalação e funcionamento. Um total de 80 \% dos alunos respondeu que compreenderam todos os processos de construção/instalação e 20\% marcaram que tiveram dificuldades em alguns pontos da construcão/instalação. 




Figura 15- Questão de ${ }^{\circ} 5$, sobre entendimento o funcionamento/instalação da cisterna.

Com relação às demais perguntas na qual eram subjetivas e foi dado possibilidade de que os alunos pudessem escrever sobre o que acharam sobre os instrumentos que foram utilizados. As questões 6,7 e 8 foram deste cunho e os resultados foram algumas colocações que seguem ma tabela 03 .

Tabela 3 - Principais colocações dos alunos nas perguntas subjetivas. Organização: Os autores.

\begin{tabular}{|c|c|}
\hline Questão & Colocação do aluno \\
\hline $\begin{array}{c}6 \text { - Importância da climatologia para estudo da } \\
\text { geográfica }\end{array}$ & $\begin{array}{l}\text { "Sim, para ter dados de diferentes locais, referentes ao clima". } \\
\text { "Sim, porque pode prevenir desmoronamentos medindo a quantidade de chuva". } \\
\text { "Sim, a climatologia define a geografia, por exemplo, o deserto com baixa umidade e alta } \\
\text { temperatura" }\end{array}$ \\
\hline $\begin{array}{l}7 \text { - Relacãao à formacacão dos tipos de chuvas, } \\
\text { qual a maior ocorrência em Itaara. }\end{array}$ & $\begin{array}{l}\text { "As chuvas de altitude, pela sua altitude de + ou menos } 400 \text { metros do nível do mar". } \\
\text { "De altitude e que é maior que a de Santa Maria" } \\
\text { "Cerração, temporal, porque é um lugar alto e com bastante mata e a que pode ser mais fácil } \\
\text { de ter este tipo de nevoeiro" }\end{array}$ \\
\hline 8 - Importância da Cisterna. & $\begin{array}{l}\text { "Acho que tem uma importância boa porque economiza muita água. Lavar as calçadas, } \\
\text { carro, casa, regar a horta, lavar janelas, lavar quartos entre outros" } \\
\text { "É importante porque a água da chuva que passa pela cisterna pode ser reutilizada. Por } \\
\text { exemplo: As tias da cozinha podem lavar louça e os panos" } \\
\text { "É importante pra a reutilização da chuva poupando água encanada." }\end{array}$ \\
\hline
\end{tabular}

Com relação a primeira frase da questão 6, podemos perceber que ficou pelo mecanismo didático como o diário do tempo e mine estação meteorológica, uma noção relacionada com a coleta dados, onde para definir o clima de uma determinada região. Na terceira frese em que o aluno cita: "Sim, a climatologia define a geografia, por exemplo, o deserto com baixa umidade e alta temperatura", ele tente relacionar o clima de uma determinada região como um fator de suma importância para definir a identidade geografia com o espaço geográfico real, como frase dele é comparada a questão do deserto, em que ele sabe que a contıguraçāo clımátıca desta regıão e altas temperaturas e baıxa umıdade.

Na questão 7, é perceptível que comparação com a questão da altitude, aonde na primeira e segunda frase, os alunos citam e relacionam a altitude de Itaara e comparando com a altitude de Santa Maria. Já na terceira frase, o aluno fala da questão dos temporais, relacionando a altitude, mas também fala da cerração que não é um tipo de precipitação, mas sim um tipo de nuvem. Com relação a isso, pode-se sugerir para as atividades futuras fixar mais estas diferenças para que diminuam os números de equívocos em relação a este conteúdo, que muitas vezes podem passar desapercebido pelo professor, sem o aluno tirar todas suas possíveis duvidas em sala de aula.

Por último, na questão número 8, que trata da importância da cisterna para escola ou para qualquer outro local, fica nítida a que o processo de reutilização da água é o mais importante na visão dos alunos. Na primeira frase é citada a questão de utilizar na horta água coletada pela cisterna, o que demostra a realidade de uma agricultura familiar que faz parte do espaço vivido do aluno, na segunda frase citado a reutilização pelas "tias da cozinha", que é um dos atributos que cisterna instalada na escola estará auxiliando. Na terceira frase fala de poupar água encana e assim poder diminuir os valores pagos pela distribuição da água encanada.

Com o desenvolver dos processos metodológicos pode-se perceber que os alunos participantes do projeto foram assíduos demostrando interesse os conteúdos propostos. Tanto na relação para com a construção dos instrumentos meteorológicos, bem como da cisterna

\section{Conclusões}

Em todo período do trabalho aplicado pode-se inferir que a relações entre teoria e prática são significativas para a aprendizagem cognitiva, uma vez que os educandos demonstram interesse para aquilo que se caracteriza dinâmico Desta forma, a climatologia como fator da ciência geográfica se torna uma das mais dinâmicas disciplinas em termos espacialização e compreensão.

Com relação ao diário do tempo as diferenças entre as duas escolas ficam melhor representadas na temperatura do ar, onde na escola Itaara ser mais distante do centro urbano apresenta menores temperaturas comparada com a escola Alfredo Lenhart que está localizada na área central da cidade, com menos vegetação arbórea.

Os instrumentos aplicados demostram que os educandos se interessem por poderem participar/construir e dessa forma aprender objetivamente com sua prática, o que demostram que se tiveram resultados significativos na visão da Avaliação Mediadora, uma vez que os alunos participaram de todo processo de aprendizagem. Outro ponto, seguindo está perspectiva do professor poder observar e deixar uma interação entre o meio social do aluno e um pouco do conhecimento cientifico, como por meio da estação metrológica e mini-cisterna, que ficaram fazendo parte do espaço físico das escolas.

Em relação ao questionário pode-se verificar que as práticas educativas foram satisfatórias e que cumpriram o esperado de criar e trabalhar os elementos atmosféricos de forma lúdica e com a participação dos educandos. Deste modo recomendando os profissionais da educação aplicar/construir junto com o aluno os conhecimentos não só de forma teórica, mas prática e alcançável no espaço vivido da comunidade escolar. 


\section{Agradecimentos}

O presente trabalho foi realizado com apoio do Programa Nacional de Cooperação Acadêmica da Coordenação de Aperfeiçoamento de Pessoal de Nível Superior-CAPES/Brasil- No Processo: 88881.068465/2014/01 - Projeto N ${ }^{\circ}$ 071/2013 CAPES/PROCAD.

À UFSM, pela bolsa de iniciação científica FIEX 2016.

À Fundação MO’Ã, pela parceria na educação ambiental em Itaara/RS.

\section{Referências}

SOUZA H, PEREIRA JLP. O orçamento da criança. Folha de São Paulo. 1995 maio 02; Opinião: $1^{\circ}$ Caderno.

ARMANI, G.; GALVANI, E. Avaliação do desempenho de um abrigo meteorológico de baixo custo. Revista Brasileira de Agrometeorologia, Piracicaba-SP, v. 14, n.1, p. 116-122, 2006.

AYOADE, J. O. Introdução à climatologia para os trópicos. Rio de Janeiro; 17 eds. Bertrand Brasil, 2013.

CALLAI, H. C. O. Ensino de geografia: recortes espaciais para análise. In: CASTROGIOVANNI, A. C. ET. AL. (Orgs.) Geografia em sala de aula, práticas e reflexões. Porto Alegre: Associação dos Geógrafos Brasileiros, Seção Porto Alegre 1998.

DOTTO, B. C; O Uso de Jogos de RPG na gestão de conflitos socioambientais e proteção do geopratrimônio hídrico no município de Itaara/ Rs. Dissertação de mestrado, Centro de Ciências Naturais e Exatas, Programa de Pôs Graduação em Geografia e Geociências, RS, 2016.

HOFFMANN, J. O Jogo Contraio da Avaliação. 9. ed. Porto Alegre, RS: Mediação, 2014.

FERREIRA; J.S; ALMEIDA; M.C. Construção de uma mini cisterna de baixo custo para captação de água da chuva para fins não $\quad$ potáveis. $2015 . \quad$ Disponível em http://www.confea.org.br/media/Civil_construcao_de_uma_mini_cisterna_de_baixo_custo_para_captacao_de_agua_da _chuva_para_fins_nao_potaveis.pdf. Ācesso em outubro de 2016

FREIRE, P.; FREI BETTO. Essa escola chamada vida. 7. Ed. São Paulo: Ática,1991.

HOPPE, I.; IENSSE, A. C.; SIMIONI, J. P. D.; WOLLMANN, C. A. Comparação entre um abrigo meteorológico de baixo custo e a estação meteorológica oficial no INMET, em Santa Maria (RS). Revista Ciência e Natura, Santa Maria, v. 37. Ed. Especial SIC, 2015, p. 132 - 137.

IBGE. Histórico do Município. 2010. Disponível em http://cidades.ibge.gov.br/painel/historico.php? lang=\&codmun=431053\&search=rio-grande-do-sul|itaara|infograficos:-historico. Acesso em outubro de 2016

MONTEIRO, C. A. F. A Frente Polar Atlântica e as chuvas na fachada sul - oriental do Brasil. São Paulo: Instituto de Geografia da USP, 1969. Série Teses e monografias 1969.

MONTEIRO, C. A. F. O estudo geográfico do clima. Cadernos Geográficos. Florianópolis, ano I,n. 1, maio, 1999

ONU. Relatório do Desenvolvimento Humano 2011: Sustentabilidade e Equidade:Um Futuro Melhor para Todos.Copyright (C) 2011 pelo Programa das Nações Unidas para o Desenvolvimento 1 UN Plaza, New York, NY 10017, USA.ISBN: 978-92-1-626010-1

SARTORI, M. G. B.Clima e percepção geográfica: Fundamentos teóricos à percepção climática e à bioclimatologia humana. Santa Maria, Pallotti 2014. S251c.

STEINKE, E. T. Produção científica a respeito do Ensino de Climatologia nos simpósios brasileiros de climatologia geográfica. STEINKE, V. A; VASCONCELOS, V.C. Revista Brasileira de Climatologia. Ano 10, vol. 14, 2014 , pg. 132-153

ROSSATO, M. S.; SILVA, D.L.M. Da cotidianidade do tempo meteorológico à compreensão de conceitos climatológicos. In: REGO, N.; CATROGIOVANNI, A.C; KAERCHER, N.A (Orgs.). Geografia: praticas pedagógicas para o Ensino Médio. Porto Alegre: Artmed, 2007.p.103-110. 